STUDIA PRAWNO-EKONOMICZNE, t. CIV, 2017

PL ISSN 0081-6841; e-ISSN 2450-8179 s. 303-314

DOI: 10.26485/SPE/2017/104/17

Izabela OSTOJ*

\title{
REDUKCJA REGULACJI CZASU PRACY JAKO KIERUNEK ZMIAN W SFERZE INSTYTUCJONALNEJ RYNKU PRACY
}

\section{(Streszczenie)}

Celem artykułu jest zbadanie zakresu redukcji współczesnych regulacji czasu pracy na świecie jako potencjalnego źródła podniesienia elastyczności rynku pracy. Dostarczono w nim argumentów na potwierdzenie tezy, iż regulacje czasu pracy są współcześnie wykorzystywane w wielu krajach jako instrument uelastycznienia rynku pracy. Ponadto zweryfikowano hipotezę cząstkową o korelacji pomiędzy stopniem swobody pracodawców w zakresie kształtowania czasu pracy a średnią liczbą godzin przepracowanych przez pracownika rocznie, która okazała się bardzo słaba. Wynika z tego, że redukcja restrykcyjności regulacji czasu pracy nie musi skutkować rzeczywistym wzrostem liczby przepracowanych godzin. Stanowi raczej rodzaj amortyzatora dla przedsiębiorstw na wypadek zmiany warunków gospodarowania.

Słowa kluczowe: rynek pracy; czas pracy; elastyczność rynku pracy

Klasyfikacja JEL: J810.

\section{Wstęp}

Obserwacje kierunków zmian w sferze instytucjonalnej rynku pracy w ostatnich latach w różnych regionach świata ujawniają w części z nich redukcję regulacji czasu pracy, co można traktować jako sposób na uelastycznienie rynku pracy. Celem artykułu jest zbadanie zakresu redukcji współczesnych regulacji czasu pracy na świecie jako potencjalnego źródła podniesienia elastyczności rynku pracy. Dostarczono w nim argumentów na potwierdzenie tezy, iż regulacje czasu pracy są współcześnie wykorzystywane w wielu krajach jako instrument uela-

* Dr hab., Uniwersytet Ekonomiczny w Katowicach, Wydział Ekonomii; e-mail: izabela.ostoj@, ue.katowice.pl 
stycznienia rynku pracy, co może stanowić ważną konstatację dla krajów UE. Ponadto zweryfikowano hipotezę cząstkową o korelacji pomiędzy stopniem swobody pracodawców w zakresie kształtowania czasu pracy a średnią liczbą godzin przepracowanych przez pracownika rocznie, co może być pośrednio dowodem na zakres wykorzystania instytucjonalnej swobody pracodawców w tym obszarze.

Artykuł składa się z czterech części. W pierwszej przedstawiono elastyczność czasu pracy jako składową elastyczności rynku pracy, w drugiej - objaśniono istotę i sposób pomiaru restrykcyjności regulacji rynku pracy, w trzeciej wyodrębniono kraje, w których w ciągu ostatniego dziesięciolecia nastąpiło zmniejszenie restrykcyjności regulacji czasu pracy, natomiast w czwartej - zbadano korelacje pomiędzy poziomem wskaźnika regulacji czasu pracy a przeciętną liczbą godzin przepracowanych przez statystycznego pracującego w ciagu roku, z wyodrębnieniem pracowników najemnych. W badaniach wykorzystano materiały i dane Instytutu Frasera oraz OECD.

\section{Elastyczność czasu pracy jako składowa elastyczności rynku pracy}

W ujęciu teoretycznym w neoklasycznym modelu przedsiębiorstwa pracodawcy zwiększają popyt na pracę do poziomu, przy którym wartość krańcowego przychodu z dodatkowej godziny pracy zrówna się z kosztem wynagrodzenia. Zakłada się zatem, że czas pracy jest w pełni elastyczny ${ }^{1}$.

W praktyce czas pracy jest regulowany i możliwość wydłużenia lub skrócenia czasu pracy bądź też zastosowania elastycznych form jego organizacji jest ograniczona. W ten sposób regulacje ograniczają elastyczność czasu pracy i stanowią istotny element infrastruktury instytucjonalnej rynku pracy, mający wpływ na elastyczność rynku pracy, czyli jego zdolność dostosowawczą do zmieniających się warunków². Elastyczność czasu pracy jako składową elastyczności rynku pracy przedstawiono na rysunku 1.

Elastyczność czasu pracy można scharakteryzować jako jeden z wymiarów wewnętrznej elastyczności popytu na pracę, realizowany w ramach przedsiębiorstwa wykorzystującego obowiązujące regulacje do dopasowania czasu pracy do potrzeb organizacji, zwykle z uwzględnieniem możliwości i preferencji pracowników. Elastyczność czasu pracy może odnosić się do wymiaru czasu pracy

1 T. Boeri, J. van Ours, Ekonomia niedoskonatych rynków pracy, Oficyna a Wolters Kluwer business, Warszawa 2011, s. 145.

2 E. Kryńska, E. Kwiatkowski, Podstawy wiedzy o rynku pracy, Wydawnictwo Uniwersytetu Łódzkiego, Łódź 2013, s. 169. 
(np. praca w niepełnym wymiarze, w tym job sharing, godziny nadliczbowe, praca w dni wolne) oraz do organizacji czasu pracy przy danym jego wymiarze (np. system przerywanego czasu pracy lub system równoważnego czasu pracy w ramach ustalonego okresu rozliczeniowego czasu pracy) ${ }^{3}$. Oznacza ona odejście od tzw. standardu normalnego czasu pracy, czyli pracy w pełnym i stałym wymiarze dziennym, przy zakazie pracy w godzinach i dniach uznawanych za szkodliwe społecznie (np. w godzinach nocnych, w dni wolne od pracy), pełniąc funkcję amortyzatora w dobie narastania niepewności warunków gospodarowania ${ }^{4}$.

RYSUNEK 1: Elastyczność czasu pracy jako składowa elastyczności rynku pracy

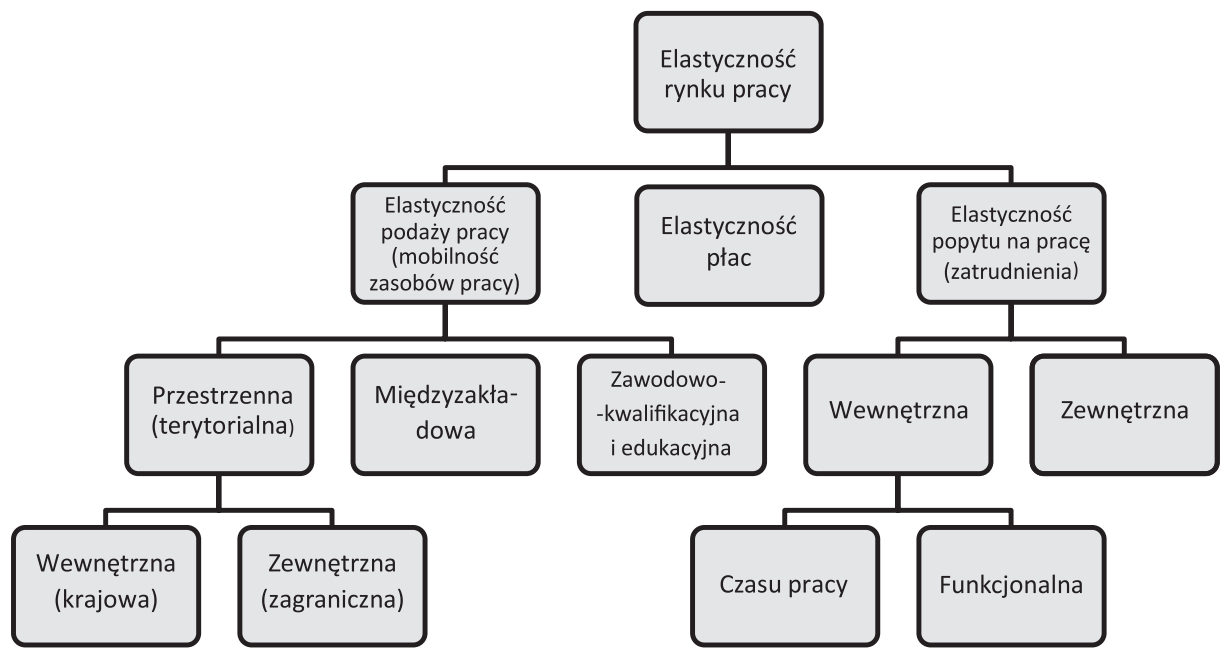

Ź r ó d ł o: opracowano na podstawie: E. Kryńska, E. Kwiatkowski, Podstawy wiedzy o rynku pracy, Wydawnictwo Uniwersytetu Łódzkiego, Łódź 2013, s. 170-180.

Elastyczność czasu pracy może odgrywać rolę istotnego czynnika ograniczającego redukcję i stabilizującego zatrudnienie w przedsiębiorstwach w okresach spowolnienia gospodarczego. Może być zatem czynnikiem budującym jeden z ważnych wymiarów bezpieczeństwa pracy, jakim jest pewność miejsca pracy.

Z. Hajn, Elastyczność popytu na pracę w Polsce. Aspekty prawne, w: E. Kryńska (red.), Elastyczne formy zatrudnienia i organizacji pracy a popyt na pracę w Polsce, IPiSS, Warszawa 2003, s. 80.

4 M. Bednarski, Czas pracy w polskiej gospodarce. Ewolucja, jej przyczyny i konsekwencje zmian, w: L. Hardt, D. Milczarek-Andrzejewska (red.), Ekonomia jest piękna, Wydawnictwo Naukowe Scholar, Warszawa 2015, s. 141-142. 
Taką rolę może spełniać np. wydłużenie rozliczeniowego okresu czasu pracy, pozwalającego na kumulację nadwyżek i deficytów przepracowanego czasu i rozliczanie ich (czyli kompensowanie nadwyżek czasem wolnym) w dłuższym okresie np. kilku miesięcy lub roku. Rozwiązania te skutkują zwykle ograniczeniem zatrudnienia terminowego i sezonowego, choć ich wpływ na ograniczenie podziału na pierwotny i wtórny segmenty rynku pracy nie został wystarczająco zbadany ${ }^{5}$. Dopuszczalność elastycznych form organizacji czasu pracy i jego wymiaru (zwłaszcza wydłużania) są współcześnie traktowane jako warunek podniesienia konkurencyjności przedsiębiorstw i gospodarek w warunkach globalizacji ${ }^{6}$. Możliwość ich stosowania zależy od obowiązujących krajowych regulacji.

\section{Istota i pomiar restrykcyjności regulacji czasu pracy}

W ciagu ostatnich kilkunastu lat $\mathrm{w}$ związku $\mathrm{z}$ rozwojem nietypowych, elastycznych form zatrudnienia można było odnieść wrażenie, że regulacje czasu pracy straciły na znaczeniu, gdyż równolegle zaczęły funkcjonować dopuszczalne rozwiązania, jak np. umowy cywilnoprawne, samozatrudnienie, umowy agencyjne, które jako formy zatrudnienia niepracowniczego im nie podlegały, a jednocześnie gwarantowały zewnętrzną elastyczność zatrudnienia. Narastające problemy społeczne związane z niestandardowymi formami zatrudnienia, takie jak rozszerzający się problem prekariatu, braku istotnych zabezpieczeń społecznych (np. ubezpieczenia chorobowego, płatnego urlopu wypoczynkowego), niestabilności zatrudnienia i inne formy narastającego ryzyka elastyczności ${ }^{7}$ skłaniają do większego zainteresowania regulacjami czasu pracy i tkwiącymi w nich rezerwami elastyczności rynku pracy.

Regulacje czasu pracy będące wyrazem interwencji państwa w stosunki pracy i przejawem ich instytucjonalizacji w warunkach nierównowagi sił pomiędzy pracodawcami a pracobiorcami pełnią funkcje ochronne w stosunku do pracowników. Mogą one przybierać postać powszechnie obowiązujących przepisów prawa lub

\footnotetext{
W. Eichhorst, P. Marx, C. Wehner, Labor Market Reforms in Europe: Towards More Flexicure Labor Markets?, IZA Discussion Paper No. 9863, 2016, s. 21.

6 H. Strzemińska, Zarządzanie zasobami czasu pracy. Doświadczenia krajów europejskich, IPiSS, Warszawa 2003, s. 182; H. Strzemińska, Czas pracy w nowej gospodarce. Trendy i formy organizacji, w: H. Strzemińska, M. Bednarski (red.), Czynnik czasu w nowej gospodarce. W jakim kierunku zmierzamy, IPiSS, Warszawa 2015, s. 30.

7 E. Giermanowska, Ryzyko elastyczności czy elastyczność ryzyka, Wydawnictwa Uniwersytetu Warszawskiego, Warszawa 2013, s. 119.
} 
być rezultatem kompromisów osiaganych w porozumieniach zbiorowych ${ }^{8}$. Doświadczenie pokazuje jednak, że siła przetargowa pracownika w odniesieniu do godzin pracy jest z reguły znacznie mniejsza niż w odniesieniu do płac, dlatego zasadnicze kwestie czasu pracy są elementem tzw. bazowych regulacji ${ }^{9}$.

Regulacje czasu pracy najczęściej sprowadzają się do określenia normalnej i maksymalnej długości tygodnia roboczego oraz ograniczeń dotyczących godzin nadliczbowych. Zalicza się do nich także przepisy określające wysokość dodatku za nadgodziny, a także przepisy regulujące długość okresu rozliczeniowego czasu pracy oraz zasady wykorzystania (organizacji) czasu pracy ${ }^{10}$. Uregulowania wymagają także praca $w$ godzinach nocnych i $w$ dni wolne od pracy. $Z$ reguły są to wielkości precyzyjnie określone w przepisach prawa. Ich restrykcyjność jednak bardzo trudno zmierzyć.

Naprzeciw temu problemowi wychodzi wskaźnik regulacji czasu pracy (WRCP) opracowany przez Instytut Frasera, będący składową wskaźnika regulacji rynku pracy (elementu wskaźnika wolności gospodarczej). Jest liczony w oparciu o dane Banku Światowego. WRCP w skali od 0 do 10 (10 - maksymalna swoboda) wyraża ocenę pięciu zmiennych: 1) ograniczenia pracy w nocy (w tym wysokość dodatku); 2) ograniczenia pracy w dni wolne (w tym wysokość dodatku); 3) możliwości wydłużenia tygodnia roboczego do 5,5 dni; 4) możliwości wydłużenia tygodnia roboczego powyżej 50 godzin, łącznie z nadliczbowymi przez 2 miesiące w ciagu roku z powodu sezonowego wzrostu produkcji; 5) wymiaru płatnego urlopu wypoczynkowego 21 dni lub krótszy ${ }^{11}$. WRC uwzględnia zatem elastyczność wymiaru czasu pracy, nie odnosząc się do organizacji czasu pracy. Mimo to jest jedyną miarą dającą możliwość porównania stopnia restrykcyjności regulacji czasu pracy pomiędzy krajami w skali świata. Można przyjąć, że spełnienie wymienionych warunków oznacza maksymalny zakres swobody decyzji przedsiębiorców w zakresie regulacji czasu pracy według współczesnych standardów.

8 H. Strzemińska, Elastyczny czas pracy - funkcje gospodarcze, dochodowe, socjalne na przykładzie Francji, Niemiec i Holandii, w: K. Frieske (red.), Deregulacja polskiego rynku pracy, IPiSS, Warszawa 2003, s. 140.

9 R.M. La Jeunesse, An Institutionalist Approach to Work Time. Is Labor Truly Irksome?, w: D.P.Champlin, J.T. Knoedler (red.), The Institutionalist Tradition in Labor Economics, M.E. Sharpe Armonk, New York, London, England 2004, s. 166.

10 T. Boeri, J. van Ours, Ekonomia ..., s. 143; E. Kryńska, E. Kwiatkowski, Podstawy..., s. 171.

11 J. Gwartney, R. Lawson, J. Hall, Economic Freedom of the World. 2015 Annual Report, Fraser Institute, 2015, s. 213. 


\section{Redukcja regulacji czasu pracy}

W celu oceny skali redukcji regulacji czasu pracy dokonano przeglądu WRCP wszystkich krajów świata, aby wyselekcjonować gospodarki lub ich grupy o największej swobodzie regulacji czasu pracy (WRCP $=10)$, a także krajów, w których uległy one liberalizacji od 2005 r., osiagając poziom w podanym przedziale (tabela 1). Kraje dodatkowo pogrupowano według kontynentów w sposób ułatwiający identyfikację regionalną.

TABELA 1: Kraje o maksymalnej wolności regulacji czasu pracy (2013 r.) i w których WRCP wzróst w latach 2005-2013

\begin{tabular}{|c|c|}
\hline $\begin{array}{l}\text { Kraje o maksymalnej wolności regulacji czasu pracy } \\
\qquad \text { WRCP }=10(2013 \text { r.) }\end{array}$ & $\begin{array}{l}\text { Kraje, w których wolność } \\
\text { regulacji czasu pracy wzrosła } \\
\text { w latach 2005-2013 }\end{array}$ \\
\hline $\begin{array}{l}\text { Europa: } \\
\text { w tym UE: Czechy, Cypr, Irlandia; } \\
\text { pozostałe: Bośnia i Hercegowina, Serbia. } \\
\text { Ameryka Południowa i Środkowa: Argentyna, Be- } \\
\text { lize, Chile, Kolumbia, Jamajka, Gujana, Haiti, Peru, } \\
\text { Surinam, Trinidad i Tobago. } \\
\text { Ameryka Północna: Kanada, Meksyk, USA. } \\
\text { Azja: } \\
\text { w tym WNP: Armenia, Kirgistan, Kazachstan; } \\
\text { Bliski Wschód: Liban, Jordania, Arabia Saudyjska; } \\
\text { pozostałe: Bangladesz, Bhutan, Brunei, Chiny, } \\
\text { Kambodża, Hongkong, Indonezja, Japonia, Malezja, } \\
\text { Myanmar, Nepal, Nowa Zelandia, Filipiny, Singapur, } \\
\text { Tajwan, Tajlandia, Wietnam. } \\
\text { Oceania: Fiji, Papua Nowa Gwinea, Timor. } \\
\text { Afryka: Botswana, Etiopia, Gabon, Malawi, } \\
\text { Mauritius, Namibia, Nigeria, Ruanda, Suazi, } \\
\text { Tanzania, Tunezja. }\end{array}$ & $\begin{array}{l}\mathbf{8}<\text { WRCP } \leq \mathbf{1 0} \text { Bośnia i Hercegowi- } \\
\text { na, Serbia Argentyna, Gujana, Haiti, } \\
\text { Kolumbia, Peru, Meksyk, } \\
\text { Armenia, Kazachstan, Kirgistan, } \\
\text { Chiny, Japonia, Mongolia, Tajwan, } \\
\text { Wietnam Etiopia, Mauritius, } \\
\text { Namibia, Ruanda, Tanzania, Tunezja. } \\
\\
\mathbf{7}<\text { WRCP } \leq \mathbf{8} \text { - Austria, Bułgaria, } \\
\text { Finlandia, Holandia, Litwa, Łotwa, } \\
\text { Niemcy, Polska, Rumunia, Słowenia, } \\
\text { Włochy, Macedonia, Turcja, Ekwador, } \\
\text { Gwinea Bissau, Kostaryka, Paragwaj, } \\
\text { Iran, Korea Płd., Burundi, Madaga- } \\
\text { skar, Maroko, Kongo, Togo, Zambia. } \\
\text { 6< WRCP } \leq 7 \text { Boliwia. } \\
\text { WRCP = 6 - Brazylia, Niger, Panama, } \\
\text { Portugalia, Senegal, Hiszpania. }\end{array}$ \\
\hline
\end{tabular}

Ź r ó d ł o: opracowano na podstawie: J. Gwartney, R. Lawson, J. Hall, Economic Freedom of the World. 2015 Annual Report, Fraser Institute, 2015.

Maksymalną swobodę regulacji czasu pracy odnotowano w 55 krajach świata. Są wśród nich kraje wysoko rozwinięte i te na niskim poziomie rozwoju, w tym znaczna liczba krajów azjatyckich oraz obu Ameryk. Można to wythumaczyć „kulturą długiego czasu pracy”, silną zwłaszcza w krajach Azji Południowo- 
-Wschodniej oraz akceptacją krótkich urlopów wypoczynkowych ${ }^{12}$ - uwarunkowaniami nieobecnymi w innych regionach świata. Dodatkowym czynnikiem w krajach słabo rozwiniętych jest niska wydajność pracy i wynikające z niej społeczne przyzwolenie na wydłużanie czasu pracy ${ }^{13}$.

Stosunkowo liczną grupę wśród krajów o maksymalnym WRCP stanowią też kraje Ameryki Południowej, w których większa swoboda regulacji jest skutkiem reform strukturalnych ukierunkowanych m.in. na uelastycznienie rynku pracy, które były realizowane głównie w latach 90. XX w. (w Chile od końca lat 70.) w dążeniu do poprawy międzynarodowej konkurencyjności gospodarek tej grupy państw ${ }^{14}$. W Argentynie, Kolumbii i Peru wzrost swobody regulacji czasu pracy nastąpił w okresie od 2005 r. Wśród krajów o maksymalnej swobodzie regulacji czasu pracy zwraca uwagę niewielka liczba krajów europejskich (5), a zaledwie trzy państwa członkowskie UE. Regulacje czasu pracy były zatem przez dość liczną grupę krajów (łącznie 55 krajów, w których nastąpiło zmniejszenie ich restrykcyjności od 2005 r.) wykorzystywane jako sposób na podniesienie elastyczności rynku pracy. Były wśród nich także kraje UE, przy czym redukcja restrykcyjności regulacji czasu pracy ukształtowała WRCP głównie w przedziale 7-8 (11 krajów). Znakiem zmian w podejściu UE do regulacji czasu pracy jest rezygnacja przez niektóre kraje członkowskie z części podstawowych zapisów europejskiej dyrektywy w sprawie czasu pra$\mathrm{cy}^{15}$ poprzez wykorzystanie derogacji. Szczególnie pięć krajów UE stosuje je szeroko, niezależnie od branż i zawodów, są to: Bułgaria, Estonia, Cypr, Malta i Wielka Brytania ${ }^{16}$.

12 Przykładowo - w Tajlandii wymiar urlopu wypoczynkowego wynosi 6 dni, na Filipinach - 5, w Indonezji - 12 dni, nawet po 20 latach pracy, a najdłuższy wymiar urlopu w tym regionie ma Nowa Zelandia - 20 dni. W USA nie obowiązuje uniwersalny wymiar urlopu wypoczynkowego, w Kanadzie wynosi 10 dni. Doing Business. Labor Market Regulation, http://www. doingbusiness.org/data/exploretopics/labor-market-regulation; stan na 24.05.2016 r.

13 J.C. Messenger, N. Ray, The Distribution of Hour of Work in Developed and Developing Countries: What are the Main Differences and Why?, ILO, Travail Policy Brief 2013/5.

14 I. Ostoj, Sfera instytucjonalna rynku pracy krajów Ameryki Łacińskiej, w: S. Swadźba (red.), Systemowe uwarunkowania wzrostu i rozwoju gospodarczego krajów Ameryki Łacińskiej (monografia w druku).

15 The Working Time Directive 2003/88/EC, http://eur-lex.europa.eu/legal-content/pl/ TXT/?uri=CELEX:32003L0088; stan na 03.06.2016 r.

16 Eurofound, Opting out of the European Working Time Directive, Publications Office of the European Union, Luxembourg 2015, s. 5. 


\section{Wskaźnik regulacji czasu pracy a czas faktycznie przepracowany}

Nie ma pewności, czy zmniejszenie restrykcyjności regulacji czasu pracy będzie skutkowało wydłużeniem czasu faktycznie przepracowanego. Na potrzebę badania związku pomiędzy restrykcyjnością regulacji czasu pracy a faktycznie przepracowaną liczbą godzin zwrócili uwagę S. Lee i D. Mc Cann, którzy skonstruowali wskaźnik efektywnej regulacji czasu pracy, będący średnią znormalizowanych wartości wskaźnika restrykcyjności ustawowego tygodniowego wymiaru czasu pracy oraz odsetka pracujących w wymiarze nieprzekraczającym ustawowego tygodnia roboczego ${ }^{17}$. Wskaźnik ten informuje do pewnego stopnia o dopasowaniu restrykcyjności regulacji czasu pracy do potrzeb gospodarki, nie pomaga jednak w ustaleniu stopnia, w jakim ustawowa długość tygodnia pracy jest przekraczana. Nie uwzględnia też innych ograniczeń związanych z czasem pracy, omawianych wyżej w konstrukcji wskaźnika regulacji czasu pracy (WRCP) liczonego przez Instytut Frasera.

TABELA 2: Wskaźnik regulacji czasu pracy i liczba przepracowanych godzin na pracownika rocznie wg OECD $w 2013 r$.

\begin{tabular}{|l|c|c|c|}
\hline \multicolumn{1}{|c|}{ Kraj } & WRCP & $\begin{array}{c}\text { Liczba godzin rocznie } \\
\text { na pracującego }\end{array}$ & $\begin{array}{c}\text { Liczba godzin rocznie } \\
\text { na pracownika najemnego }\end{array}$ \\
\hline Australia & 8 & 1663 & b.d. \\
\hline Austria & 8 & 1629 & 1445 \\
\hline Belgia & 6 & 1576 & 2085 \\
\hline Chile & 10 & 2015 & 1825 \\
\hline Czechy & 10 & 1763 & 1370 \\
\hline Dania & 8 & 1438 & 2019 \\
\hline Estonia & 4 & 1866 & 1568 \\
\hline Finlandia & 8 & 1643 & 1389 \\
\hline Francja & 2 & 1474 & 1727 \\
\hline Grecja & 4 & 2060 & 1648 \\
\hline Hiszpania & 6 & 1699 & 1346 \\
\hline Holandia & 8 & 1421 & 1460 \\
\hline Irlandia & 10 & 1815 & 1809 \\
\hline Islandia & 8 & 1846 & \\
\hline
\end{tabular}

17 S. Lee, D. Mc Cann, Measuring Labour Market Institutions: Conceptual and Methodological Questions on Working Hours Rigidity, w: J. Berg, D. Kucera (red.), In Defence on Labour Market Institutions: Cultivating Justice in the Developing World, Palgrave Macmillan, New York 2008, s. 49. 


\begin{tabular}{|l|c|c|c|}
\hline \multicolumn{1}{|c|}{ Kraj } & WRCP & $\begin{array}{c}\text { Liczba godzin rocznie } \\
\text { na pracującego }\end{array}$ & $\begin{array}{c}\text { Liczba godzin rocznie } \\
\text { na pracownika najemnego }\end{array}$ \\
\hline Izrael & 8 & 1867 & b.d. \\
\hline Japonia & 10 & 1734 & 1746 \\
\hline Kanada & 10 & 1708 & 2071 \\
\hline Korea & 8 & 2079 & 1622 \\
\hline Luksemburg & 4 & 1649 & 2328 \\
\hline Meksyk & 10 & 2237 & 1291 \\
\hline Niemcy & 8 & 1363 & b.d. \\
\hline Norwegia & 4 & 1408 & 1747 \\
\hline Nowa Zelandia & 10 & 1752 & 1879 \\
\hline Polska & 8 & 1918 & 1693 \\
\hline Portugalia & 6 & 1852 & 1736 \\
\hline Rosja & 6 & 1980 & 1493 \\
\hline Słowacja & 8 & 1772 & b.d. \\
\hline Słowenia & 8 & 1550 & b.d. \\
\hline Szwajcaria & 6 & 1576 & 1795 \\
\hline Szwecja & 6 & 1607 & 1803 \\
\hline USA & 10 & 1788 & 1655 \\
\hline Węgry & 4 & 1880 & 1478 \\
\hline Wielka Brytania & 8 & 1669 & \\
\hline Włochy & 8 & 1733 & \\
\hline
\end{tabular}

Ź r ó d ł o: dane OECD, https://data.oecd.org/emp/hours-worked.htm (10.05.2016) oraz J. Gwartney, R. Lawson, J. Hall, Economic Freedom of the World. 2015 Annual Report, Fraser Institute, 2015.

Niżej podjęto próbę zbadania związku pomiędzy restrykcyjnością regulacji czasu pracy a liczbą przepracowanych godzin. Rozróżniono liczbę przepracowanych godzin rocznie w przeliczeniu na pracującego i liczbę godzin pracy przypadającą na pracownika najemnego. Można przyjąć, że niższy stopień restrykcyjności regulacji czasu pracy (wyższy poziom WRCP), któremu będzie towarzyszyła większa liczba godzin rocznie przepracowanych przez pracownika najemnego, będzie sygnałem, iż pracodawcy wykorzystują instytucjonalne możliwości wydłużania czasu pracy. Ze względu na ograniczony dostęp do danych przykładowe obliczenia wykonano dla wybranych krajów na podstawie danych OECD o liczbie przepracowanych godzin rocznie (tabela 2). Statystyczny związek pomiędzy wymienionymi wielkościami można określić na podstawie współczynnika korelacji między nimi (tabela 3). 
TABELA 3: Współczynniki korelacji między wskaźnikami regulacji czasu pracy a liczba godzin przepracowanych w ciagu roku wg OECD w 2013 r.

\begin{tabular}{|l|c|}
\hline \multicolumn{1}{|c|}{ Zmienna } & Wskaźnik regulacji czasu pracy \\
\hline $\begin{array}{l}\text { Liczba przepracowanych godzin przypadająca } \\
\text { na pracującego rocznie }\end{array}$ & 0,19 \\
\hline $\begin{array}{l}\text { Liczba przepracowanych godzin przypadająca } \\
\text { na pracownika najemnego rocznie }\end{array}$ & 0,14 \\
\hline
\end{tabular}

Ź r ó d ł o: obliczenia własne na podstawie danych OECD: https://data.oecd.org/emp/hours-worked. htm (10.05.2016) oraz J. Gwartney, R. Lawson, J. Hall, Economic Freedom of the World. 2015 Annual Report, Fraser Institute, 2015.

Współczynniki korelacji są dodatnie, ale bardzo niskie. Nieco wyższy jest współczynnik korelacji dla pracujących ogółem niż dla zatrudnienia pracownika najemnego, co nie potwierdza wykorzystywania przez pracodawców instytucjonalnej swobody do wydłużania czasu pracy zatrudnionych pracowników $\mathrm{w}$ analizowanym okresie. Zjawisko w większym stopniu dotyczyło wszystkich pracujących, co mogło mieć związek z ogólnym poziomem aktywności gospodarczej. Statystyka t $(\alpha=0,05)$ wykazała natomiast brak korelacji poziomu liczby przepracowanych godzin rocznie zarówno przypadających na pracującego, jak i na pracownika najemnego z poziomem wskaźnika regulacji czasu pracy. Problem wymaga dalszych, bardziej zaawansowanych badań.

\section{Zakończenie}

J.M. Keynes przewidywał, że w XXI w. pracownicy doczekają czasów, w których trzygodzinna dniówka albo piętnastogodzinny tydzień pracy będą całkowicie wystarczające, by usatysfakcjonować większość z nas ${ }^{18}$. Zanim to jednak nastąpi, wydaje się, że konieczne jest uelastycznienie podejścia do czasu pracy.

Przeprowadzona analiza pozwala na wyciagnięcie wniosku, że maksymalna swoboda regulacji czasu pracy, mierzona WRCP była charakterystyczna dla wybranych regionów świata - Azji i obu Ameryk. Regulacje czasu pracy w ciagu ostatnich 10 lat w wielu krajach świata uległy też redukcji. W mniejszym stopniu dotyczyło to Europy, zwłaszcza krajów UE, w których wprawdzie redukcja także postępowała, ale dokonywała się w średnich przedziałach restrykcyjności. Jedyne kraje UE, które charakteryzują się maksymalną swobodą regulacji czasu pracy to Czechy, Cypr i Irlandia.

18 J.M. Keynes, Essays in Persuasion, Palgrave Macmillan, New York 2010, s. 329. 
Stworzenie formalnej możliwości przejściowego wydłużenia czasu pracy nie oznacza, że musi ona być w pełni wykorzystywana przez przedsiębiorstwa. Stanowi raczej rodzaj amortyzatora na wypadek zmiany warunków gospodarowania. Jak wykazano, niska restrykcyjność regulacji czasu pracy nie przekłada się w stopniu statystycznie istotnym na wzrost liczby przepracowanych godzin w ciągu roku w przeliczeniu na pracownika najemnego, czyli redukcja restrykcyjności regulacji w tym zakresie nie musi skutkować rzeczywistym wydłużeniem czasu pracy. Wynika to z przykładowych obliczeń przeprowadzonych na podstawie danych OECD. Podjęty problem wymaga jednak dalszych pogłębionych badań.

\section{Bibliografia}

\section{Opracowania}

Bednarski Marek, Czas pracy w polskiej gospodarce. Ewolucja, jej przyczyny i konsekwencje zmian, w: Łukasz Hardt, Dominika Milczarek-Andrzejewska (red.), Ekonomia jest piękna, Wydawnictwo Naukowe Scholar, Warszawa 2015, s. 139-152.

Boeri Tito, van Ours Jan, Ekonomia niedoskonatych rynków pracy, Oficyna a Wolters Kluwer business, Warszawa 2011.

Eichhorst Werner, Marx Paul, Wehner Caroline, Labor Market Reforms in Europe: Towards More Flexicure Labor Markets?, IZA Discussion Paper No. 9863, 2016.

Eurofound, Opting out of the European Working Time Directive, Publications Office of the European Union, Luxembourg 2015.

Giermanowska Ewa, Ryzyko elastyczności czy elastyczność ryzyka, Wydawnictwa Uniwersytetu Warszawskiego, Warszawa 2013.

Gwartney James, Lawson Robert, Hall Joshua, Economic Freedom of the World. 2015 Annual Report, Fraser Institute, 2015.

Hajn Zbigniew, Elastyczność popytu na pracę w Polsce. Aspekty prawne, w: Elżbieta Kryńska (red.), Elastyczne formy zatrudnienia i organizacji pracy a popyt na prace w Polsce, IPiSS, Warszawa 2003, s. 48-99.

Keynes John M., Essays in Persuasion, Palgrave Macmillan, New York 2010.

Kryńska Elżbieta, Kwiatkowski Eugeniusz, Podstawy wiedzy o rynku pracy, Wydawnictwo Uniwersytetu Łódzkiego, Łódź 2013.

La Jeunesse Robert M., An Institutionalist Approach to Work Time. Is Labor Truly Irksome?, w: Dell P. Champlin, Janet T. Knoedler, The Institutionalist Tradition in Labor Economics, M.E. Sharpe Armonk, New York, London, England 2004, s. 159-175.

Lee Sangheon, Mc Cann Devidre, Measuring Labour Market Institutions: Conceptual and Methodological Questions on Working Hours Rigidity, w: Janine Berg, David Kucera (red.), In Defence on Labour Market Institutions: Cultivating Justice in the Developing World, Palgrave Macmillan, New York 2008, s. 32-63.

Messenger Jon C., Ray Nikhil, The Distribution of Hour of Work in Developed and Developing Countries: What are the Main Differences and Why?, ILO, Travail Policy Brief 2013/5. 
Ostoj Izabela, Sfera instytucjonalna rynku pracy krajów Ameryki Łacińskiej, w: Stanisław Swadźba (red.), Systemowe uwarunkowania wzrostu i rozwoju gospodarczego krajów Ameryki Łacińskiej (monografia w druku).

Strzemińska Helena, Czas pracy w nowej gospodarce. Trendy i formy organizacji, w: Helena Strzemińska, Marek Bednarski (red.) Czynnik czasu w nowej gospodarce. W jakim kierunku zmierzamy?, IPiSS, Warszawa 2015, s. 18-50.

Strzemińska Helena, Elastyczny czas pracy - funkcje gospodarcze, dochodowe, socjalne na przykładzie Francji, Niemiec i Holandii, w: Kazimierz Frieske (red.), Deregulacja polskiego rynku pracy, IPiSS, Warszawa 2003, s. 130-141.

Strzemińska Helena, Zarządzanie zasobami czasu pracy. Doświadczenia krajów europejskich, IPiSS, Warszawa 2003.

\section{Strony internetowe}

Doing Business. Labor Market Regulation, http://www.doingbusiness.org/data/exploretopics/ labor-market-regulation; stan na 24.05.2016 r.

OECD, https://data.oecd.org/emp/hours-worked.htm; stan na 10.05.2016 r.

The Working Time Directive 2003/88/EC, http://eur-lex.europa.eu/legal-content/pl/TXT/?uri= CELEX:32003L0088; stan na 03.06.2016 r.

Izabela OSTOJ

\section{REDUCTION OF WORKING TIME REGULATIONS AS A TENDENCY IN INSTITUTIONAL SPHERE OF THE LABOR MARKET}

( Sum mary)

The paper aims to examine the extent of reduction in current working time regulations across the world as a potential source of increasing the elasticity of the labor market. It provides the arguments supporting the thesis which states that working time regulations actually serve as a mean to make the labor market more flexible. Moreover, the partial hypothesis about the correlation between the degree of freedom given to the employers in determining the working time of their employees and average time spent at work per year was verified. The correlation transpired to be quite low, which implies that reduction in working time regulations does not have to result in increase of hours spent at work but rather acts as a mechanism for the amortization of any economic shocks enterprises are exposed to.

Keywords: labour market; working time; labour market flexibility 